\title{
Primary cutaneous mucormycosis in an immunocompetent patient
}

\author{
Mihai Paduraru, ${ }^{1}$ Carlos Moreno-Sanz, ${ }^{2}$ Jose Maria Olalla Gallardo ${ }^{3}$
}

${ }^{1}$ Department of General Surgery, General Hospital of Tomelloso, Tomelloso, Spain ${ }^{2}$ Cirugia General y Digestiva Hospital La Mancha Centro, Alcazar de San Juan, Spain ${ }^{3}$ Hospital La Mancha Centro, Alcazar de San Juan, Spain

\section{Correspondence to}

Mihai Paduraru,

paduraru_mihai@yahoo.com

Accepted 2 August 2016
CrossMark

To cite: Paduraru $\mathrm{M}$, Moreno-Sanz C, Olalla Gallardo JM. BMJ Case Rep Published online: [please include Day Month Year] doi:10.1136/bcr-2016214982

\section{SUMMARY}

Mucormycosis is most common in immunocompromised patients, but it can also occur in healthy hosts, most frequently as primary cutaneous mucormycosis (PCM) and predominantly as a result of skin trauma. We present an uncommon case of PCM in a healthy, young man with no previous history of local trauma. Despite rapid progression of the infection, the patient was successfully treated through surgical intervention and by administering liposomal amphotericin B and posaconazole. He made a full recovery without the need for skin grafting.

\section{BACKGROUND}

Mucormycosis refers to fungal infection caused by the order Mucorales. The organisms are often found in soil or decaying vegetation. They enter the body via the air, gastrointestinally or traumatised skin. ${ }^{1}$ Incidents involving immunocompetent hosts are rare, with $80 \%$ of all cases occurring in immunocompromised patients. ${ }^{2}$

Cutaneous is the third most commonly occurring type of mucormycosis, representing $19 \%$ of all cases. Half of these are in immunocompetent hosts $^{3}$ with more infrequent presentation in patients with no evident skin lesion.

Primary cutaneous mucormycosis (PCM) can affect cutaneous and subcutaneous layers, fascia and even the muscles beneath. If the diagnosis is not made early and dissemination occurs, then it could be fatal. ${ }^{4}$

\section{CASE PRESENTATION}

A 25 -year-old man was first evaluated through the emergency department for an erythematous plaque on his left anterior thigh, $\sim 3 \times 4 \mathrm{~cm}$ in size, which had appeared 24-48 hours previously. There was no sign of any local trauma or insect bite, blistering or other symptoms.

The patient, a veterinary technician administering vaccines in a farm environment, had no previous history of medical or surgical disease.

Amoxicillin/clavulanic acid $875 \mathrm{mg} / 125 \mathrm{mg}$ oral were prescribed, and an outpatient consultation appointment was made.

After 5 days, the inflamed area had extended in size to $10 \times 10 \mathrm{~cm}$ with localised pain, but no fever. The patient was admitted to the hospital's surgical department for intravenous broad-spectrum empirical antibiotic (piperacillin-taozobactam 4/0.5 g intravenously every 6 hours) and analgesia, with a diagnosis of soft tissue cellulites in extension (figure 1).
Over the course of the next 3 days, the affected area developed blisters with pus, fluctuation and a circular central necrosis of $4 \times 4 \mathrm{~cm}$ (figure 2). The necrotic area was surgically removed. Pus, mucus and liquid fat were noticed below the skin and raised suspicion of a particular infection. The affected skin layer was elevated from the fascia; lavage and debridement were performed and drainage tubes were inserted (figure 3). After the surgery, the wound was dressed and cleaned twice per day using saline solution $0.9 \%$ and betadine.

\section{INVESTIGATIONS}

Resected soft tissue (skin and fat) was sent for histopathological analysis, and liquid was withdrawn for microbiological culture growth. A histopathological examination with H\&E staining revealed abundant fungal-shaped structures with broad hyphae in the subcutaneous fat; twisted (not

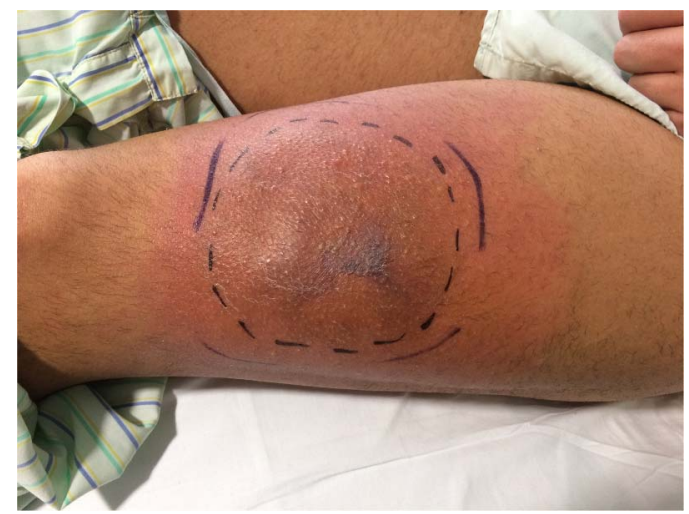

Figure 1 Marked area denotes extent of the inflammation on admission.

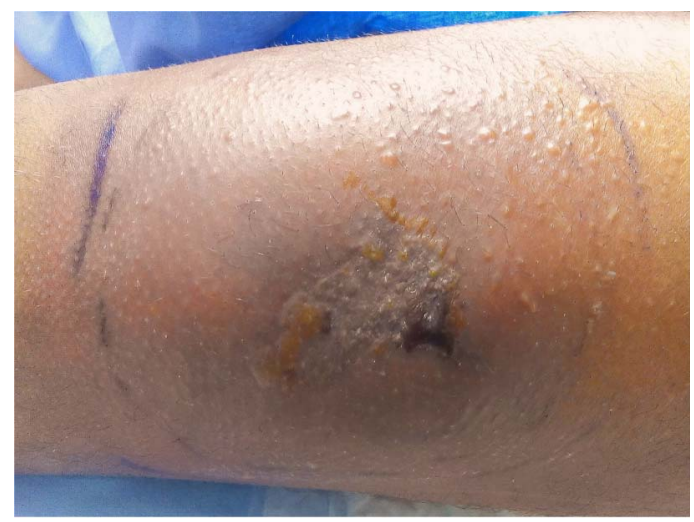

Figure 2 Three days after admission-extent of the fluctuant region with central necrosis and blistering with pus and blood. 


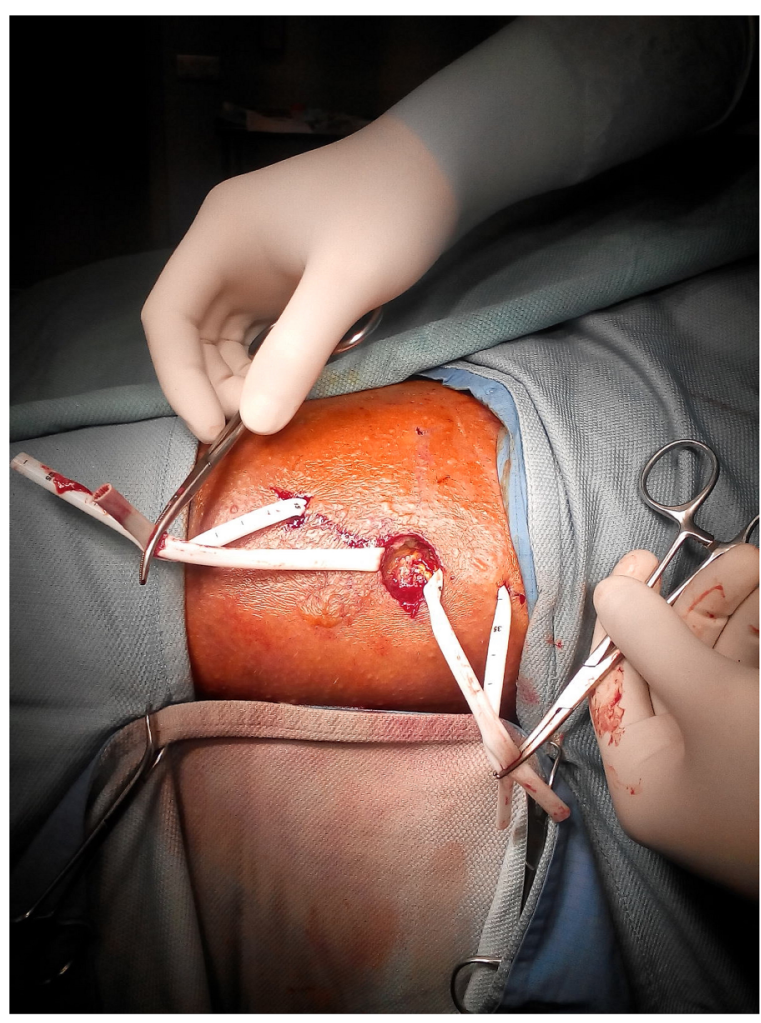

Figure 3 Central necrosis excision and insertion of two drainage tubes to facilitate skin elevation and cleaning.

septate) and with regular branching at right angles (figure 4).

A clear trend towards angioinvasion of the microorganism was noticed, with abundant fungal elements infiltrating the entire vessel wall and occupying the lumen, with necrosis of adjacent tissue (figure 5).

All these elements were consistent with a diagnosis of Mucorales genera infection, more specifically, mucormycosis. The microbiological culture from the liquid and tissue sample was sterile using conventional methods.

Tests were also performed to determine the immunity status of the patient. Immunoglobulins (IgA/E/G/M), proteinogram and complete blood count with cell morphology were all normal. HIV and viral hepatitis tests were negative.

\section{DIFFERENTIAL DIAGNOSIS}

The initial clinical suspicion was of a common skin infection. Invasive fungal infections that could present as primary cutaneous are aspergillosis, monilia and mucormycosis, with differentiation being made between septate and non-septate hyphae using histopathological examination. ${ }^{5}$ Aspergillus forms finer chambered hyphae, with frequent septation and prone to branch at acute angles $\left(45^{\circ}\right)$. Monilia forms spores with elongated pseudohyphae branches, which are smaller. The hyphae of mucorales are distinct and allow for a presumptive identification from clinical specimens. ${ }^{1}$ Mucorales also have the tendency to angioinvasion, an important element in diagnosis.

\section{TREATMENT}

On the basis of this evidence, the patient was administered liposomal amphotericin B from postoperative day 11. The initial dosage was $5 \mathrm{mg} / \mathrm{kg} /$ day (weight, $99.5 \mathrm{~kg}$ ) under internal medicine observation.

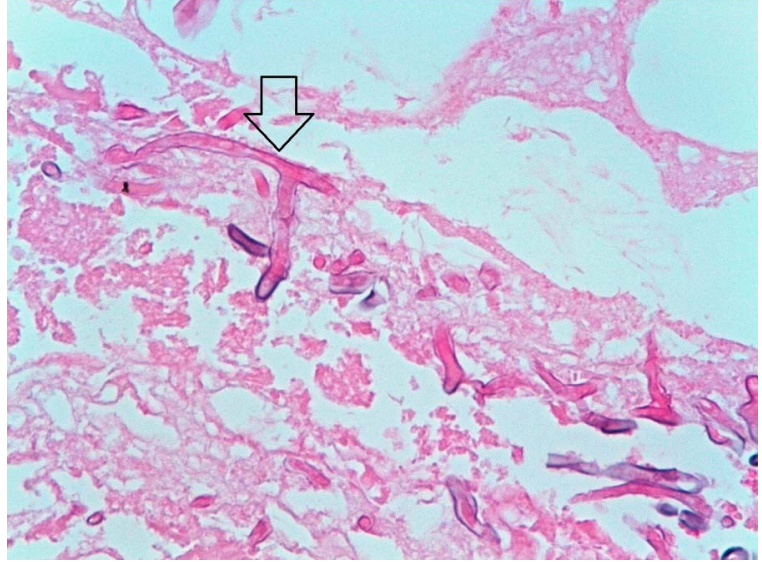

Figure 4 Morphology of compatible hyphae: fungal structures of broad, twisted, non-septate hyphae, with regular branching at right angles, consistent with Mucorales genera (H\&E staining, $\times 400$ ).

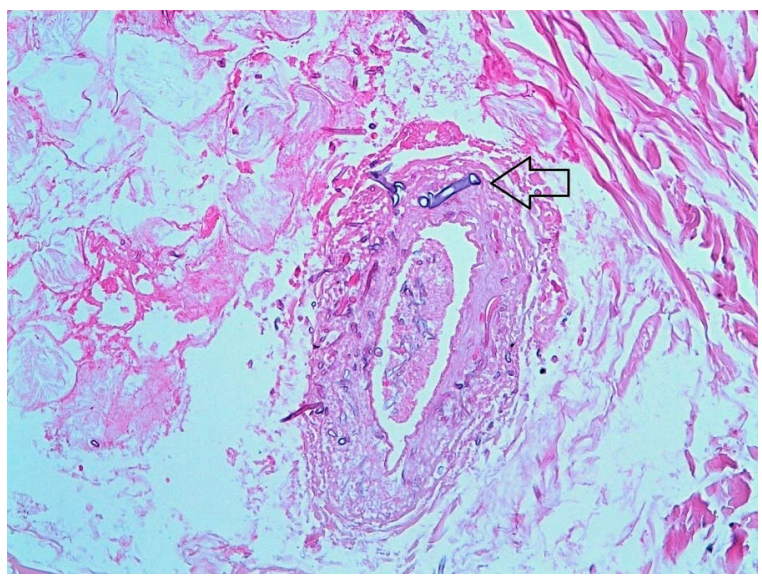

Figure 5 Angioinvasion: necrotic subcutaneous fat without inflammatory reaction; clearly visible fungal elements invading vessel wall and occupying lumen in the centre of the field (H\&E staining, $\times 200)$.

Over the following days, the patient began to make progress, with a reduction in the inflammation and re-adhesion of the skin. Renal function started to slightly deteriorate, and the dosage of liposomal amphotericin B was reduced to $3 \mathrm{mg} / \mathrm{kg} /$ day from postoperative day 15 .

\section{OUTCOME AND FOLLOW-UP}

The patient was discharged on postoperative day 26 with significant improvement of the wound, no secretion and with a superficial skin defect of $2 \mathrm{~cm}$. Liposomal amphotericin B was replaced by posaconazole $400 \mathrm{mg}$ oral suspension for the first day and $200 \mathrm{mg}(5 \mathrm{~mL})$ thereafter for 1 month. Follow-up was performed by internal medicine and the operating surgeon for 2 months after discharge (figure 6).

\section{DISCUSSION}

Cutaneous mucormycosis is an emerging mycosis, with increasing incidence in the last two decades. ${ }^{6}$ Clinical features include erythema, vesicles and pustules, ulceration and necrotic cellulites. Prognosis is favourable if dissemination does not occur. The reference standard for diagnosis is from biopsy and culture growth. However, because culture growth is positive in only 


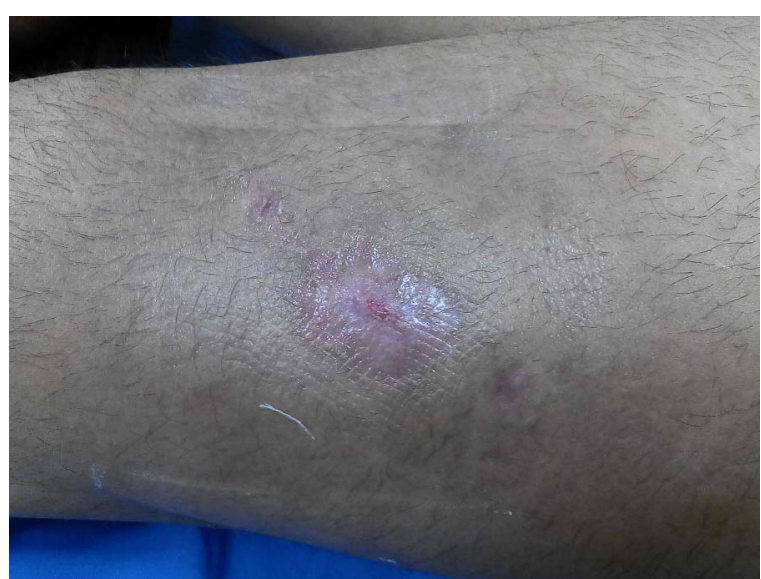

Figure 6 Wound status at 25th postoperative day.

$15-25 \%$ of cases, ${ }^{6}$ authors agree that confirmation can be obtained when broad, non-septate hyphae are observed in histological specimens obtained from the necrotic region and where angioinvasion is present. ${ }^{7}$

Owing to the potential severity of the infection, it is advisable to initiate treatment as soon as a diagnosis is suspected and while pursuing confirmation of this diagnosis. ${ }^{8}$ In our case, the specific treatment was initiated only after the diagnosis was made. A particular kind of infection was suspected after surgery; however, we did not anticipate mucormycosis in a young healthy patient.

Standard treatment for PCM is thorough surgical debridement and antifungal agent administration. In our case, the less aggressive surgical approach minimised tissue damage. Surgical elevation of the skin from the muscle fascia prevented invasion into the muscle and limited resection of the necrotic tissue, thereby preventing the need for skin grafting.

Monitoring the dosage of liposomal amphotericin B in order to prevent deterioration of renal function, even in young, healthy patients, is important. Although there was no clear evidence as to how our patient contracted the disease, we compared our case with others reported in the literature. We found 34 clearly reported cases of PCM in immunocompetent adult hosts between the years 1991 and 2015, with the majority $(62 \%)$ being in Asia. Forty-one per cent of cases had been infected through soil contamination, usually as a result of traffic accidents or falls. Bites and thorn pricks accounted for $15 \%$ of incidence in the literature and could have been the method of contraction in our case, even if we did not see any corresponding marks. A case occurring in an Indian vet with no history of trauma and affecting the abdominal wall was also found. ${ }^{9}$ Thirty-five per cent of the case reports noted the occupation of the host, and in the majority of incidents, these were farm related. We found a single case reported in Spain attributed to an insect bite. ${ }^{10}$

Despite this speculation, it is difficult to conclude with any certainty how our patient might have contracted the disease.
Twelve per cent of the cases reported could find no obvious reason for the contraction of PCM.

\section{Patient's perspective}

At first, I thought it was a simple infection and would be cured quickly without me having to stay in the hospital. I did not expect to have surgery, the infection to be a rare one and me to stay so long admitted. However, I was happy with the treatment and, especially, with the end result.

\section{Learning points}

- Primary cutaneous mucormycosis (PCM) is a rare but emerging infection.

- Diagnosis is not initially apparent and needs to be confirmed by histopathological examination.

- Treatment should be initiated as soon as the diagnosis is suspected or made.

- A multidisciplinary approach is key to successful management.

Acknowledgements The authors acknowledge the valuable contribution of Melanie Radcliff, BA, who provided assistance with the translation of this document into the English language.

Contributors MP is the main author and involved in editing, CM-S is responsible for supervision of editing and JMOG is the collaborating author.

Competing interests None declared.

Patient consent Obtained.

Provenance and peer review Not commissioned; externally peer reviewed.

\section{REFERENCES}

1 Cox GM. Mucormycosis (zygomycosis); UpToDate. 2015.

2 Roden MM, Zaoutis TE, Buchanan WL, et al. Epidemiology and outcome of zygomycosis: a review of 929 reported cases. Clin Infect Dis 2005;41:634-53.

3 Skiada A, Petrikkos G. Cutaneous mucormycosis. Skinmed 2013;11:155-9; quiz 159-60.

4 Petrikkos G, Skiada A, Lortholary 0, et al. Epidemiology and clinical manifestations of mucormycosis. Clin Infect Dis 2012;54(Suppl 1):S23-34.

5 Guarner J, Brandt ME. Histopathologic diagnosis of fungal infections in the 21st century. Clin Microbiol Rev 2011;24:247-80.

6 Spellberg B, Walsh TJ, Kontoyiannis DP, et al. Recent advances in the management of mucormycosis: from bench to bedside. Clin Infect Dis 2009;48:1743.

7 Adam RD, Hunter G, DiTomasso J, et al. Mucormycosis: emerging prominence of cutaneous infections. Clin Infect Dis 1994;19:67-76.

8 Lass-Flörl C. Zygomycosis: conventional laboratory diagnosis. Clin Microbiol Infect 2009;15(Suppl 5):60-5.

9 Kumar A, Khilnani GC, Aggarwal S, et al. Primary cutaneous mucormycosis in an immunocompetent host: report of a case. Surg Today 2003;33:319-22.

10 Coronel-Pérez I, Rodríguez-Rey E, Castilla-Guerra L, et al. Mucormicosis cutánea primaria por Saksenaea vasiformis en paciente inmunocompetente. Actas Dermosifiliogr 2015;106:516-18. 


\section{Rare disease}

Copyright 2016 BMJ Publishing Group. All rights reserved. For permission to reuse any of this content visit http://group.bmj.com/group/rights-licensing/permissions.

BMJ Case Report Fellows may re-use this article for personal use and teaching without any further permission.

Become a Fellow of BMJ Case Reports today and you can:

- Submit as many cases as you like

- Enjoy fast sympathetic peer review and rapid publication of accepted articles

- Access all the published articles

- Re-use any of the published material for personal use and teaching without further permission

For information on Institutional Fellowships contact consortiasales@bmjgroup.com

Visit casereports.bmj.com for more articles like this and to become a Fellow 